ARTIGO ORIGINAL

ISSN 1677-5090

(C) 2018 Revista de Ciências Médicas e Biológicas

DOI: http://dx.doi.org/10.9771/cmbio.v17i2.25835

\title{
Uso de cianocrilato no fechamento de excisões faciais
}

\author{
Use of cyanocrylate at closing of facials excisions \\ Sandro Cilindro de Souza ${ }^{1 *}$, Fabiana Paim Rosa ${ }^{2}$, José Valber Lima Menezes ${ }^{3}$ \\ ${ }^{1}$ MD. Cirurgião Plástico do Hospital Geral Roberto Santos - Salvador (BA), Brasil; \\ ${ }^{2}$ PhD. Professora Associada de Patologia do Instituto de Ciências da Saúde - UFBA; ${ }^{3}$ PhD. Professor Titular da \\ Faculdade de Medicina da Bahia - FMB/UFBA.
}

\begin{abstract}
Resumo
Introdução: a face é o centro estético do indivíduo. Por isso, lesões nessa região podem repercutir mais negativamente do que em qualquer outra parte do corpo. Os cianoacrilatos, devido às suas vantagens de uso, incluindo a ausência de marcas de ponto, apresentam-se como um atrativo método de fechamento de feridas faciais em suas mais diversas formas. Objetivo: avaliação da eficácia do fechamento de excisões cutâneas faciais, usando o 2-etilcianoacrilato. Metodologia: estudo retrospectivo, no qual 36 feridas foram ocluídas com 2-etilcianoacrilatocomo alternativa à sutura intradérmica. Resultados: feridas excisionais (100\%) foram tratadas com 2-etilcianoacrilato e suturas profundas relaxadoras como método de síntese. Cicatrizes inestéticas $(13,9 \%)$, deiscência $(5,6 \%)$ e infecção $(2,8 \%)$ foram os problemas encontrados. Não houve casos de necrose, reações alérgicas ou de queloide. Os resultados foram considerados satisfatórios na maioria dos pacientes $(96,4 \%)$. Conclusão: o uso do 2-etilcianoacrilato se mostrou seguro e com excelentes resultados cosméticos no grupo de pacientes selecionados.
\end{abstract}

Palavras-chave: Cianoacrilatos. Técnicas de sutura. Adhesives.

\begin{abstract}
Introduction: the face is the aesthetic center of the individual. Therefore, lesions in this region may have more negative repercussions than in any other part of the body. Cyanoacrylates (CA), due to their advantages of use, including the absence of dot marks, present themselves as an attractive method of closing facial wounds in their most diverse forms. Objective: to evaluate the efficacy of the closure of facial skin excisions using 2-ethylcyanoacrylate. Methodology: retrospective study in which 36 wounds were occluded with 2-ethylcyanoacrylate as an alternative to intradermal suture. Results: excisional wounds (100\%) were treated with 2-ethylcyanoacrylate and deep relaxation sutures as a synthesis method. Unaesthetic scars (13.9\%), dehiscence (5.6\%) infection (2.8\%) were the problems encountered. There were no cases of necrosis, allergic or keloid reactions. The results were considered satisfactory in most patients (96.4\%). Conclusion: the use of 2-ethylcyanoacrylate was safe and with excellent cosmetic results in this group of patients. Keywords: Cyanoacrylates. Suture techniques. Adhesives.
\end{abstract}

\section{INTRODUÇÃO}

O significado das lesões da pele da face decorre da localização conspícua e da importância estética e da imagem que cada pessoa tem sobre si mesma. A face é o ponto central das características físicas do ser humano (KIM et al., 2015; ZHAO et al., 2012). Ela também é a sede dos sentidos da visão, olfato e paladar e constitui o núcleo das funções vitais da fala e da mastigação. Por conseguinte, lesões faciais, mesmo as de reduzido tamanho, podem ter repercussões funcionais, emocionais, psicológicas, sociais e profissionais mais negativas do que em qualquer outra parte do corpo (KLEIN et al., 2005). Cirurgias reparadoras permitem eventualmente a correção de desequilíbrios causados pela deformação facial (WEINZWEIG, 2010).

Os cianoacrilatos (CA) têm sido os adesivos teciduais mais usados para o fechamento de feridas cutâneas. Seus diversos benefícios, vastamente evidenciados na literatura

Correspondente/Corresponding: *Sandro Cilindro de Souza - End: Av. Reitor Miguel Calmon, sala 110 - 40110-902 Vale do Canela, Salvador-BA - Tel: (71) 3283-8885 - E-mail: sandrocilin@gmail.com.br
(SINGER; THODE JUNIOR, 2004), incluem ausência de marcas de pontos, dispensa de uso de curativos e resultados cosméticos superiores (ALFERES et al., 2008; SOUZA et al., 2011). Essas vantagens colocam os CA como um dos mais atrativos métodos de fechamento de feridas faciais.

O objetivo deste estudo é avaliar o índice de complicações e os resultados estéticos resultantes do fechamento de excisões cutâneas na face, usando CA como alternativa à sutura.

\section{METODOLOGIA}

Estudo retrospectivo sobre pacientes atendidos no ambulatório de pequenas cirurgias do Hospital de Camaçari e do Hospital Roberto Santos. Não foram encontradas pendências que inviabilizem a realização da pesquisa, estando de acordo com a resolução N. 466/12 do CONEP e sendo considerada aprovada por este comitê de ética em pesquisas sob o Parecer 2.068.698.

Os critérios de inclusão foram: lesões restritas à face, feridas excisionais passíveis de fechamento por sutura 
direta (isto é, até $2,0 \mathrm{~cm}$ de largura) e uso de CA como método de fechamento. Foram excluídos os pacientes não operados pela especialidade de Cirurgia Plástica e aqueles cujos dados de prontuário foram incompletos. As variáveis avaliadas foram: idade, gênero, etiologia e localização das lesões, tempo de cirurgia, extensão dos fechamentos, complicações pós-operatórias e satisfação dos pacientes com o tratamento.

Os dados foram inseridos em planilha do software Microsoft Office Excel (Microsoft Corporation) para armazenamento e análise estatística descritiva.

\section{RESULTADOS}

Em um intervalo de aproximadamente 12 anos (31/05/2005 a 31/03/17), foram operados 153 pacientes, sendo 40 deles $(26,1 \%)$ submetidos a fechamento das excisões usando o ECA (2-etilcianoacrilato - Epiglu ${ }^{\circledR}$, Meyer-Haake, Germany). Destes últimos casos, 28 pacientes (70,0\%) tiveram suas lesões removidas da face.

A caracterização da população estudada e detalhes técnicos do procedimento podem ser observados na Tabela 1.

Tabela 1 - População e procedimentos

\begin{tabular}{|c|c|c|c|c|}
\hline amostra & \multicolumn{2}{|c|}{28 pacientes, 36 excisões } & & \\
\hline idade & \multicolumn{2}{|c|}{15 a 85 anos, média 38,7 anos } & & \\
\hline peso & \multicolumn{2}{|c|}{43 a $89 \mathrm{Kg}$, média $61,0 \mathrm{Kg}$} & & \\
\hline \multirow[t]{2}{*}{ sexo } & \multicolumn{2}{|l|}{ feminino } & & $89,7 \%(25)$ \\
\hline & \multicolumn{2}{|l|}{ masculino } & & $10,7 \%(3)$ \\
\hline tempo cirúrgico & \multicolumn{2}{|c|}{3,3 a $36,7 \mathrm{~min}$, média $15,3 \mathrm{~min}$} & & \\
\hline extensão das colagens & \multicolumn{2}{|c|}{2 a $6 \mathrm{~cm}$, média $3,7 \mathrm{~cm}$ (outlier: $9,5 \mathrm{~cm}$ ) } & & \\
\hline \multirow[t]{4}{*}{ distribuição } & \multicolumn{2}{|l|}{$1 / 3$ superior (fronte) } & & $8,3 \%(3)$ \\
\hline & \multicolumn{2}{|c|}{ 1/3 médio (nariz, zigomas, bochechas e lábios) } & & $69,4 \%(25)$ \\
\hline & \multicolumn{2}{|l|}{$1 / 3$ inferior (queixo) } & & $8,3 \%(3)$ \\
\hline & \multicolumn{2}{|l|}{ não especificado } & & $13,9 \%(5)$ \\
\hline \multirow[t]{5}{*}{ lesão } & \multicolumn{2}{|l|}{ nódulos a esclarecer } & & $47,2 \%(17)$ \\
\hline & \multicolumn{2}{|l|}{ sinais (pintas) } & & $25,0 \%(9)$ \\
\hline & \multicolumn{2}{|l|}{ fissura auricular } & & $13,9 \%(5)$ \\
\hline & \multicolumn{2}{|l|}{ cicatriz } & & $11,1 \%(4)$ \\
\hline & \multicolumn{2}{|l|}{ excesso de pele } & & $2,8 \%(1)$ \\
\hline \multirow[t]{6}{*}{ histopatologia } & \multicolumn{2}{|l|}{ não realizada } & & $72,2 \%(26)$ \\
\hline & \multicolumn{2}{|l|}{ nevo intradérmico } & & $11,1 \%(4)$ \\
\hline & \multirow{2}{*}{ cisto } & \multirow{2}{*}{$8,3 \%(3)$} & epidérmico: & $5,6 \%(2)$ \\
\hline & & & sebáceo: & $2,7 \%(1)$ \\
\hline & \multirow{2}{*}{ ceratose } & \multirow{2}{*}{$8,3 \%(3)$} & seborreica: & $5,6 \%(2)$ \\
\hline & & & actínica: & $2,7 \%(1)$ \\
\hline \multirow[t]{3}{*}{ complicações } & \multicolumn{2}{|l|}{ distúrbio cicatricial } & & $13,9 \%(5)$ \\
\hline & \multicolumn{2}{|l|}{ deiscência } & & $5,6 \%(2)$ \\
\hline & \multicolumn{2}{|l|}{ infecção } & & $2,8 \%(1)$ \\
\hline
\end{tabular}

Fonte: Dados da pesquisa.

$\mathrm{O}$ ato operatório básico usado em todos os procedimentos cirúrgicos foi sumarizado na Figura 1 . O registro dos resultados estéticos, segundo a satisfação pessoal das pacientes, está representado na Figura 2. A Figura 3 mostra um caso cirúrgico encontrado no presente estudo.

No pós-operatório, não foram encontradas recomen- dações do uso de curativos ou de antibióticos profiláticos. Os pacientes $(96,4 \%$ - 27) foram acompanhados por um período máximo de 90 dias. Nessa última avaliação, como método de avaliação dos resultados, os pacientes foram indagados se estavam satisfeitos com os resultados da cirurgia. 
Figura 1 - Técnica cirúrgica. A: lesão cutânea, B: excisão elípti$c a, C$ : sutura subdérmica, D: sutura intradérmica e colagem, $E$ : lesão fechada com CA

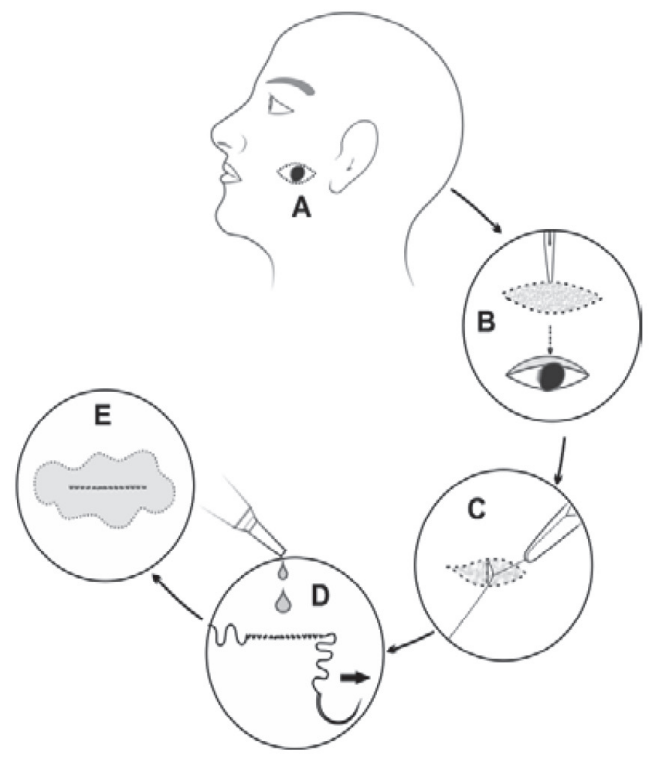

Figura 2 - Resultados pós-operatórios

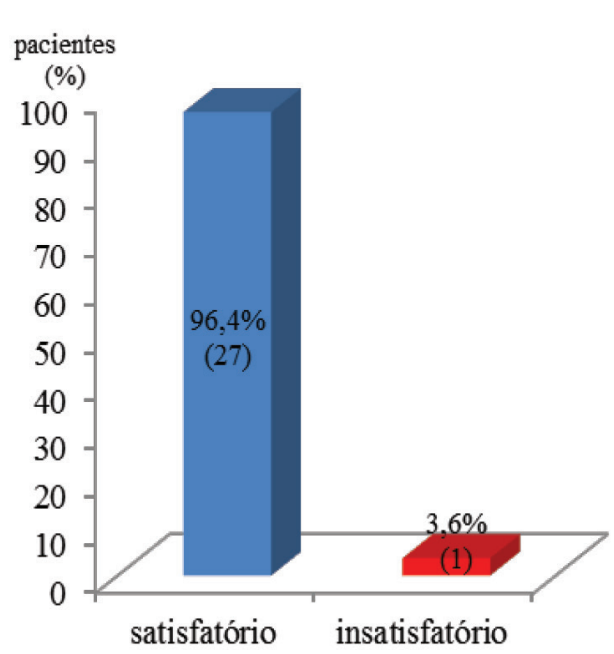

Fonte: Dados da pesquisa

Fonte: Dados da pesquisa

Figura 3 - Paciente de 44 anos com nevos intradérmicos (04). Aspecto pré-operatório (A), excisão elíptica (B), pós-operatório imediato com colagem $(C)$ e pós-operatório de 3 meses $(D)$.

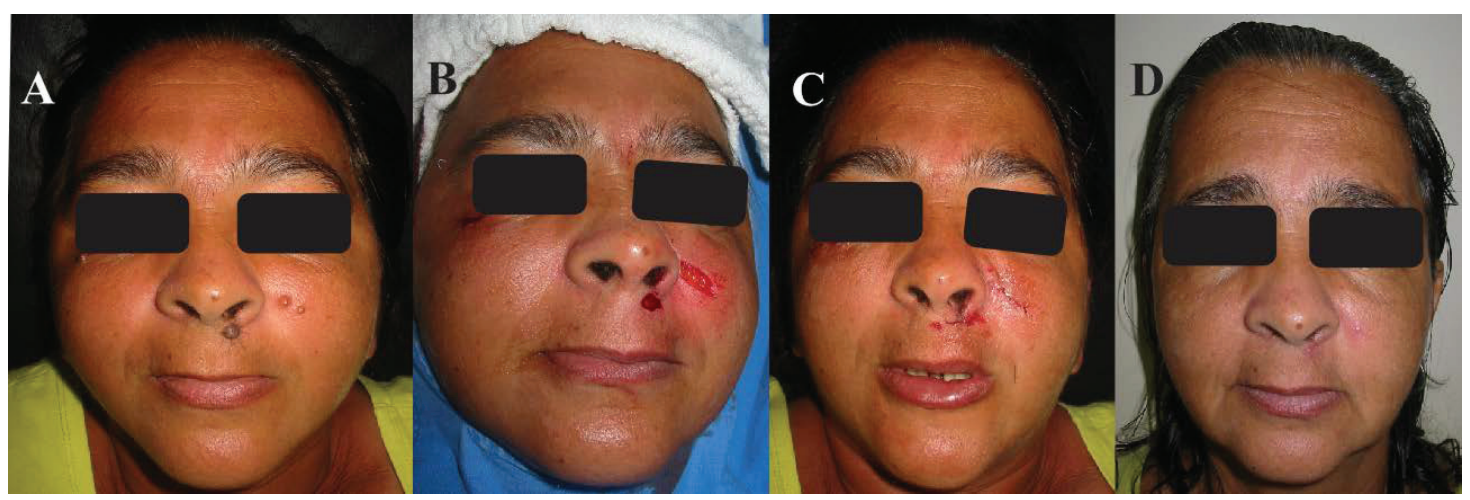

Fonte: Fotos de paciente.

\section{DISCUSSÃO}

O ECA como adesivo tissular tem sido usado com resultados satisfatórios na maioria das especialidades cirúrgicas, incluindo as cirurgias estéticas (ALFERES et al., 2008; D’ASSUNÇÃO, 2008; SINGER; THODE JUNIOR, 2004; SOUZA et al., 2011; WEINZWEIG, 2010). Em uma reação exotérmica espontânea, essas substâncias se polimerizam a partir de um monômero, o éster cianoacrílico $\mathrm{CH}_{2}=\mathrm{C}(\mathrm{CN})$ COO-R. A película resultante liga fortemente os aderentes como uma ponte, com uma força tênsil similar a de uma sutura com fios de nylon 5-0 (KIM et al., 2015; SINGER; THODE JUNIOR, 2004). Estudos com ECA mostram que o produto não é carcinogênico (PASCUAL et al., 2016). Inflamações agudas e crônicas, seroma, citotoxicidade in vitro, necrose, leuconíquia e dermatite alérgica de contato têm sido problemas atribuídos ao uso de ECA em pele (ILGENFRITZ NETO et al., 2017; PASCUAL et al., 2016; SINGER; THODE JUNIOR, 2004). No entanto, diversos trabalhos têm evidenciado que os efeitos desfavoráveis do uso de CA em pele restringem-se a complicações locais discretas, em especial inflamações e deiscências parciais, sendo provavelmente devido às próprias cirurgias e não ao uso específico do adesivo (CALOI; MANGANELLO SOUZA, 2005; ILGENFRITZ NETO et al., 2017; SINGER; THODE JUNIOR, 2004; SOUZA et al., 2011).

A principal desvantagem dos CA é a cito-histotoxicidade, manifesta por meio de citólise in vitro e formação de reações inflamatórias agudas ou crônicas in vivo (PASCUAL 
et al., 2016; SOUZA et al., 2011). A toxicidade é atribuída à metabolização com liberação de produtos de degradação (formaldeído e acetato). Os derivados de menor cadeia têm mostrado maior histotoxicidade do que os de cadeia maior porque se degradam mais rapidamente. O ECA tem mostrado gerar uma menor resposta histotóxica em relação a outros CA de cadeia curta e à sutura (ILGENFRITZ NETO et al., 2017; SOUZA et al., 2011). O efeito histotóxico se restringe a tecidos profundos e bem vascularizados, de modo que o uso de CA tem sido recomendado apenas para superfícies avasculares, como a da pele (KIM et al., 2015; SINGER; THODE JUNIOR, 2004;)

$O$ uso dos CA tem sido considerado seguro devido ao seu baixo índice de complicações (D’ASSUNÇÃO, 2008; SINGER; THODE JUNIOR, 2004; SOUZA et al., 2011). As baixas taxas de infecção têm sido atribuídas à reduzida deposição de corpos estranhos na ferida e ao efeito bactericida do produto. As reações alérgicas são raras. O ECA possui qualidades comuns a outros $C A$, tais como resistência à ação de exsudados, força capaz de suportar até $500 \mathrm{~g}$ de tração, rápida polimerização e efeito selante, bactericida e hemostático (SINGER; THODE JUNIOR, 2004; SOUZA et al., 2011).

No presente estudo, a maior parte dos pacientes submetidos a pequenas cirurgias $(73,9 \%$ - 113$)$ não fizeram uso do CA. A principal causa foi à disponibilidade limitada do produto devido ao seu elevado custo $(€ 81,74)$. A despeito de suas inúmeras vantagens, esse tem sido o principal motivo responsável pela baixa utilização dos CA na maioria dos hospitais públicos do País (ILGENFRITZ NETO et al., 2017; SINGER; THODE JUNIOR, 2004; SOUZA et al., 2011). Ademais, dentre as formulações de CA aprovadas para uso médico (2-butil-cianoacrilato, 2-octil-cianoacrilato e 2-etilcianoacrilato), o ECA é a mais recente e, por isso, a usada com menos frequência (ALFERES et al., 2008).

A excisão elíptica é a técnica mais empregada para lesões da pele. Se a elipse cutânea removida for demasiadamente curta, formam-se ears dogs que não desaparecem espontaneamente. Por isso, a formação dessas dobras de pele deve ser evitada, fazendo-se uma elipse com duas a três vezes a largura da lesão cutânea (WEINZWEIG, 2010). Seguindo essa recomendação, a lesão excisada de maior largura encontrada no corrente estudo (um nevo) foi de $2,0 \mathrm{~cm}$, o que resultou em uma colagem de $6 \mathrm{~cm}$ de extensão. No entanto, a maior colagem encontrada nesta pesquisa $(10 \mathrm{~cm})$ foi resultado da remoção de uma seção de pele redundante em nariz em um paciente idoso $(9,5$ $\mathrm{cm}$ de extensão por $0,5 \mathrm{~cm}$ de largura).

De acordo com os dados colhidos no presente estudo, as lesões tratadas foram, sobretudo, pequenos nódulos benignos $(47,2 \%)$ localizados na face média $(69,4 \%)$. Essa é a região facial mais exposta à visualização e também a mais exposta a radiações solares, atualmente a principal causa conhecida para o desenvolvimento de alterações cutâneas benignas e malignas (ROBBINS et al., 2015). Por outro lado, a avaliação histopatológica das lesões foi prejudicada na corrente pesquisa, pois a maioria dos pacientes $(72,2 \%)$, a despeito de solicitações recorrentes da equipe cirúrgica, não realizou o exame até a época da última consulta médica (90 dias). As razões alegadas por eles foram perda das biópsias, esquecimento, falta de tempo e dificuldades financeiras para executar o estudo anátomo-patológico. Felizmente, a ausência desses dados não influenciou no resultado final das cirurgias ou na avaliação da satisfação cosmética geral.

A faixa etária média e a predominância de mulheres neste trabalho refletem os indivíduos mais frequentemente afetados por dermatoses, a maioria causada por exposição às intempéries ambientais e por procedimentos cirúrgicos. A experiência tem mostrado que a maior parcela dos pacientes submetidos a excisões cutâneas se situa a partir dos 30 anos, fase que, convencionalmente, inicia o envelhecimento (COELHO, 2017; WEINZWEIG, 2010). A partir dessa época, gradativamente há perda de trofismo tegumentar que na juventude constitui importante componente de afirmação social. A mulher paga o maior tributo devido às pressões de uma sociedade que cada vez mais explora a beleza feminina (SOUZA et al., 2011). Em procedimentos estéticos na face, os principais estímulos para a realização de uma cirurgia são a melhora da autoconfiança (profissional e pessoal) e alívio da sensação de envelhecimento. As cirurgias que otimizam a estética facial contribuem para a melhoria da qualidade de vida. As pacientes têm sua autoestima elevada e se sentem mais seguras para alcançar seus objetivos de vida, inclusive profissionais. Em nível psicológico, observam-se no pós-operatório menores índices de depressão e ansiedade (COELHO, 2017).

De acordo com a metodologia empregada por diversos autores, a aplicação dos CA tem se mostrado um procedimento simples, rápido e seguro (ALFERES et al., 2008; CALOI; MANGANELLO SOUZA, 2005; D'ASSUNÇÃO, 2008; KIM et al., 2015; QUINN et al., 1997; SINGER; THODE JUNIOR, 2004; SOUZA et al., 2011). Uma vez polimerizado, o CA forma sobre a ferida um revestimento flexível, translúcido, resistente e impermeável, prescindindo a remoção de pontos e a colocação de curativos. Isso reduz a necessidade de cuidados, monitorização e uso de anestésicos, resultando em custos mais baixos. As suturas podem ser molhadas a partir do dia seguinte ao reparo. $\mathrm{O}$ adesivo se solta espontaneamente entre 4 a 8 dias. Como o uso de agulhas é desnecessário, não há riscos de acidentes de punção. A polimerização instantânea possibilita a formação precoce de uma barreira mecânica que impede a penetração de sujidades e a perda de umidade na ferida, abreviando o tempo cirúrgico, facilitando a cicatrização e proporcionando rápida epitelização queratinizada. Essas vantagens tem tornado os CA o método de fechamento de pele que mais agrada aos usuários (ALFERES et al., 2008; KIM et al., 2015; SINGER; THODE JUNIOR, 2004; SOUZA et al., 2011).

As complicações encontradas na presente série foram discretas e locais. 0 índice total foi de $22,2 \%$ (8), com 
13,9\% (5) das excisões apresentando leves distúrbios cicatriciais (cicatrizes alargadas, deprimidas ou hipertróficas), 5,6\% (2) apresentando deiscência e 2,8\% (1) desenvolvendo infecção. Uma vez que a rápida permanência de contato dos CA com os tecidos pode explicar a menor reação inflamatória desencadeada pelos adesivos em relação à sutura, as cicatrizes inestéticas foram atribuídas a características locais, como pele facial muito móvel, reação inflamatória contra suturas subdérmicas relaxadoras e fechamentos contra linhas de força, fatores incontestavelmente fibrogênicos (WEINZWEIG, 2010). Por conseguinte, o índice total de complicações atribuídas pelos autores ao uso específico do CA foi de $8,4 \%$ dos fechamentos. Neste estudo, uma deiscência ocorreu por remoção acidental precoce da película do adesivo, resultando em abertura parcial da ferida. A outra deiscência ocorreu por tensão aumentada na linha de fechamento em um nível superior ao que o adesivo pôde suportar. A deiscência é uma preocupação constante com o uso dos CA e, após a histotoxicidade, é a complicação mais comum (0,3\% a 26\%) (ILGENFRITZ NETO et al., 2017; QUINN et al., 1997; SINGER; THODE JUNIOR, 2004). Sem suturas relaxadoras, a ocorrência de deiscência pode chegar até a $60 \%$ dos casos (ALFERES et al., 2008). A taxa de infecção do presente estudo foi similar à relatada na literatura pesquisada (1,1\%) (ALFERES et al., 2008; SINGER; THODE JUNIOR, 2004; SOUZA et al., 2011). O problema ocorreu em uma excisão frontal tratada com curativos, evoluindo com a formação de cicatriz linear de excelente aspecto cosmético. Em se tratando de lesões contaminadas, os CA mostram um pronunciado efeito bactericida (ILGENFRITZ NETO et al., 2017; QUINN et al., 1997; SINGER; THODE JUNIOR, 2004). O mecanismo se relaciona à parede celular, pois a sensibilidade é restrita a bactérias gram positivas, inclusive Staphylococcus aureus. A forte carga eletronegativa do polímero reage com a parede celular das bactérias gram positivas que tem carga polar positiva. As bactérias gram negativas são relativamente resistentes, porque sua membrana de lipopolissacarídeos isola a parede celular. Os CA também evitam a deposição de corpos estranho na ferida, o que potencializa seu efeito antibiótico. As suturas diminuem a quantidade de contaminação necessária para produzir infecção (KIM et al., 2015; PASCUAL et al., 2016; QUINN et al., 1997).

$\mathrm{O}$ aspecto das cicatrizes persiste como o mais importante elemento na avaliação de cirurgias cosméticas (SOUZA et al., 2011). Curiosamente, neste estudo, todas as pacientes com distúrbios cicatriciais referiram estar satisfeitas com o tratamento, possivelmente devido às dimensões reduzidas das cicatrizes cirúrgicas e à melhoria da aparência em relação às lesões previamente tratadas. Estudos clínicos revelam que uso de CA em pele têm resultado em cicatrizes com aspecto estético similar ao de suturas intradérmicas (SINGER; THODE JUNIOR, 2004).

A avaliação de resultados em cirurgias cosméticas é complexa. A própria definição do que é estético é controversa e há poucos trabalhos na literatura médica sobre a avaliação de procedimentos baseados em evidências (SOUZA et al. 2011). Diante das dificuldades, na corrente pesquisa foi usado um método fácil e prático, baseado na avaliação das próprias pacientes. Na verificação dos resultados cosméticos, a opinião da paciente é provavelmente a mais importante, uma vez que ela é quem será a pessoa modificada, tanto na realidade física de sua aparência, como na percepção de sua imagem corpórea. No presente estudo, obteve-se uma excelente taxa satisfação $(96,4 \%)$. Apenas uma paciente $(3,6 \%)$ ficou insatisfeita com 0 resultado cosmético da cirurgia; o caso foi atribuído à extensão $(5,8 \mathrm{~cm})$ e à visibilidade de sua cicatriz facial e não à ocorrência de complicações específicas relacionadas ao uso do ECA. Esses resultados animadores foram atribuídos à reduzida extensão da cirurgia, à simplicidade da técnica usada, as vantagens do uso dos CA e à reduzida taxa de complicações percebidas pelas pacientes.

A ausência da mais temida complicação relacionada com o uso de ECA (necrose), juntamente com o alto índice de satisfação dos pacientes $(96,4 \%)$, foi o achado mais expressivos deste trabalho, o que confirma a segurança do uso de CA descrita em outros estudos (ALFERES et al., 2008; 0; D'ASSUNÇÃO, 2008; SOUZA et al., 2011). A aplicação da correta técnica operatória, o uso externo em áreas de pele relaxadas por suturas subdérmicas, o contato por período curto com a superfície do corpo e a aplicação de mínima quantidade de adesivo foram os fatores atribuídos aos bons resultados aos três meses pós-operatórios.

\section{CONCLUSÃO}

O uso do ECA mostrou-se com baixo índice de complicações $(8,4 \%)$ e com resultados cosméticos satisfatórios $(96,4 \%)$ neste grupo de pacientes.

\section{REFERÊNCIAS}

ALFERES, F.C.B.A. et al. Avaliação do etil-2-cianoacrilato (Epiglu ${ }^{\circledR}$ ) na síntese de pele: estudo em ratos. Rev. Bras. Cir. Plast., São Paulo, v. 23, n. 3, p. 179-183, 2008.

CALOI, T. M.; MANGANELLO-SOUZA, L. C. Uso do cianoacrilato no fechamento cutâneo das queiloplastias primárias. Rev. Soc. Bras. Cir. Plást., São Paulo, v. 20, n. 2, p. 108-111, 2005. Lilacs identificador 411050

COELHO, F. M. et al. Cirurgia plástica estética e (in) satisfação corporal: uma visão atual. Rev. Soc. Bras. Cir. Plást., São Paulo, v. 32, n. 1, p. 135-140, 2017.

\section{DOI: 10.5935/2177-1235.2017RBCP0019}

D'ASSUNÇÃO, E. A. Cola de cianoacrilato de baixo custo em cirurgia plástica. Rev. Soc. Bras. Cir. Plást., São Paulo, v. 23, n. 1, p. 22-25, 2008.

KIM, L. Fast absorbing gut suture versus cyanoacrylate tissue adhesive in the epidermal closure of linear repairs following mohs micrographic surgery. J Clin Aesthet Dermatol., v. 8, n. 2, p. 24-29, 2015. DOI: 10.1186/1471-2490-14-93.

KLEIN, M. B. et al. Management of facial burns with a collagen/glycosaminoglycan skin substitute-prospective experience with 12 consecutive patients with large, deep facial burns. Burns, Guildford, v. 31, n. 3, p. 257- 
261, 2005. Disponível em: https://doi.org/10.1016/j.burns.2004.11.013 Acesso em: 01 mar. 2017.

ILGENFRITZ NETO, J. et al. The aplication of cyanoacrilate surgical glue on skin suture in rats. Acta cir. bras., São Paulo, v. 32, n. 1, p. 56-64, 2017. Disponível em: <http://dx.doi.org/10.1590/s0102-865020170107>. Acesso em: 05 maio 2018.

PASCUAL, G. et al. Cytotoxicity of cyanoacrylate-based tissue adhesives and short-term preclinical in vivo biocompatibility in abdominal hernia repair. Int. braz. j. urol., Rio de Janeiro, v. 42, n. 1, p. 113-117, 2016. Disponível em: <https://doi.org/10.1371/journal.pone.0157920>. Acesso em: 05 maio 2018.

QUINN, J. et al. Octylcyanoacrylate tissue adhesive vs suture repair in contaminated wound model. Surgery, [s.I], v. 122, n. 1, p. 69-72, 1997. DOI: http://dx.doi.org/10.1016/S0039-6060 (97)90266-X

ROBBINS, S. L. Pathologic basis of diseases. 9. ed. Philadelphia:
Saunders-Elsevier, 2015.

SINGER, A. J.; THODE JUNIOR., H. C. A review of the literature on octylcyanoacrylate tissue adhesive. Am J. Surg., v. 187, n. 2, p. 238-48, 2004. Disponível em: https://doi.org/10.1016/i.amjsurg.2003.11.017. Acesso em: 01 mar.2017.

SOUZA, S. C. et al. Estudo comparativo entre etilcianoacrilato e sutura intradérmica no fechamento de excisões cutâneas. Rev. Soc. Bras. Cir. Plást., São Paulo, v. 26, n. 4, p. 566-572, 2011. Disponível em: <http:// dx.doi.org/10.1590/S1983-51752011000400005>. Acesso em: 01 mar. 2017.

WEINZWEIG, J. Plastic surgery secret plus. 2. ed. Philadelphia: Mosby Elsevier, 2010.

ZHAO, J. et al. Clinical application of full-face, whole full-thickness skin grafting: a case report. J. Plast. Reconstr. Aesthet Surg., Oxford, v. 65, n. 11, p. 1576-1579, 2012. DOI: 10.1016/j.bjps.2012.04.002.

Submetido em: 06/03/2018

Aceito em: 06/06/2018 